\title{
50 Shades of Green: An Examination of Sustainability Policy on Canadian Campuses
}

\author{
Philip Vaughter \\ University of Saskatchewan \\ Tarah Wright \\ Dalhousie University \\ Yuill Herbert \\ Sustainability Solutions Group
}

\begin{abstract}
Koichiro Matsuura, Director-General of UNESCO, asserts that education is one of the most effective instruments that society can employ in the effort to adopt sustainable development. This paper is a first effort to explore the degree to which Canadian institutions of higher education, including colleges and universities, have embraced this assertion. It includes the first census of the existing environment/sustainability policies and/or plans of Canadian postsecondary institutions ( $n=220$ ), and an examination of the relationships between the existence of an environment/sustainability policy/plan and the presence of other sustainability initiatives on campus. The focus on policies and plans is timely because in public institutions like colleges and universities, actions and practices are determined by policy. The results reveal a number of patterns and insights, including, for example, the influence of provincial legislation on the uptake of policies.
\end{abstract}




\section{Résumé}

Koichiro Matsuura, directeur général de l'UNESCO, affirme que l'éducation est l'un des instruments les plus puissants que la société puisse utiliser dans un effort de développement durable. Ce document constitue un premier effort pour explorer à quel point les institutions canadiennes d'enseignement supérieur ont mis cette affirmation en pratique. Cet effort comprend le premier recensement des politiques actuelles sur l'environnement et le développement durable, et des plans des établissements canadiens d'enseignement postsecondaire $(n=220)$, ainsi qu'un examen des relations entre l'existence d'un plan/d'une politique sur l'environnement/de développement durable et la présence d'autres initiatives de développement durable sur le campus. L'accent sur les politiques et les plans se fait à point nommé parce que dans les établissements publics, tels que les collèges et les universités, les actions et les pratiques sont déterminées par la politique. Les résultats révèlent un certain nombre de motifs et de découvertes incluant, par exemple, l’influence des lois provinciales sur l'adoption des politiques.

\section{Introduction}

Human activity is having a significant impact on the planet, to the extent that scientists are no longer certain that the Earth's ecosystems can support and sustain current and future generations (Ehrlich \& Ehrlich, 2013; IPCC, 2012; Rockstrom et al., 2009; World Wildlife Fund, 2012). Sustainability and the related concept sustainable development (SD) have emerged as ways of thinking about and dealing with emergent ecological crises (Dryzek, 2005). In 1987, the Brundtland Report defined sustainable development as "meeting the needs of the present without compromising the ability of future generations to meet their own needs." (WCED, 1987 p.4). The world's political leaders pledged their support for Brundtland's position at the UN Earth Summit in Rio de Janeiro in 1992.

Scholars agree on some of the basic tenets of sustainability. Central to shared definitions is a focus on integrating ecological, economic, and social considerations into global institutional decision making. There is much debate on the interplay between these three domains, with subcategories such as strong and weak sustainability (Hopwood, Mellor, \& O'Brien, 2005) being identified. However, because the study is based on a census, such distinctions were not investigated. Sustainability concerns include intergenerational equity, intragenerational equity (increasing equity within nations and among developed and developing countries), the ecological limits to economic growth, population growth, planetary health, species extinction, climate change, and the challenge of conserving and enhancing the resource base.

Among governments and in the private sector, the term "sustainable development" predominates, while academic institutions and NGOs tend to prefer the term "sustainability" (Robinson, 2004). We did not analyze the use of "sustainability" and "sustainable development" in terms of their respective meanings in the context of higher education. In this paper, and in the broader research project that this study is a part of, we use the term "sustainability" broadly to encompass the many ways that people utilize the term, or take up sustainability issues using different terms. ${ }^{1}$ We have also included discussion of policies 
and practices that focus solely on environmental considerations. In our experience, some schools use the term "environment" when they actually mean something quite broader.

The United Nations Educational, Scientific and Cultural Organization (UNESCO) has suggested that "[e]ducation . . . is humanity's best hope and most effective asset in the effort to achieve sustainable development." (UNESCO, 1997). In recognition of its importance, UNESCO designated the period 2005-2014 as the Decade of Education for Sustainable Development (DESD). Postsecondary education (PSE) institutions are seen as important players in the movement towards the attainment of a sustainable future. Universities and colleges educate future societal leaders; as such, they have an obligation to produce graduates with an understanding of and a capacity to help solve sustainability problems (Clugston \& Clader, 1999; Cortese, 2003; Orr, 1992; Rees, 2010). In addition, universities can lead by incorporating the modelling of sustainable practices into their own physical operations. They are well positioned to accumulate and mobilize new information to confront sustainability-related problems (M'Gonigle \& Starke, 2006; Vaughter, Wright, McKenzie, \& Lidstone, 2013; Waas, Hugé, Verbruggen, \& Wright, 2011). Also, university campuses can serve as experimental teaching environments, where sustainable action, design, and policy can be modelled on behalf of the community at large (Sharp, 2002; Alshuwaikhat \& Abubakar, 2008).

This paper focuses on sustainability in postsecondary institutions (also known as higher education institutions) across Canada. A small body of literature exists that examines environment and sustainability (herein environment/sustainability) governance in Canadian postsecondary education institutions (Leduc, 2010; Moore, 2005; Wright, 2003, 2004, 2006). To date, however, neither overviews of existing high-level environment/sustainability policies in Canadian PSE institutions nor examinations of how such policies might be associated with other sustainability initiatives on campuses have been produced. The present study attempts to fill this gap in the literature by providing a census of existing environment/sustainability policies at all accredited PSE institutions in Canada $(n=220)$. These institutions represent the combined memberships of the Association of Universities and Colleges in Canada (AUCC) and the Association of Canadian Community Colleges (ACCC).

Canadian PSE institutions have responded to the sustainability challenge in a variety of ways. Over the past 30 years, there has been a proliferation of declarations aimed at furthering sustainability in higher education (e.g., the Talloires Declaration (1990) and the Halifax Declaration (1991), the Kyoto Declaration on Sustainable Development (1993), the Copernicus University Charter (1994), the Association of Canadian Community Colleges' Pan-Canadian Protocol for Sustainability (2009) the Climate Change Statement of Action for Canada (2008), and Ontario Universities Committed to a Greener World (2009)) of which many colleges and universities have become signatories, (Lozano et al., 2013; Sylvestre, McNeil, \& Wright, 2013; Wright, 2004). These documents outline the intentions of colleges and universities to work toward implementing sustainability within their institutions through: environmental literacy initiatives; curriculum development; research; partnering with government, with nongovernmental organizations, and with industry in the development of sustainability initiatives; and "greening" physical operations (Wright, 2003; Bartlett \& Chase, 2004). In Canada, there is a growing tendency for PSE institutions to become signatories to such international declarations, which commit the institution to becoming more sustainable (Wright, 2011). 
There has also been an increase in the number of campus sustainability offices and/or officers in PSE institutions in Canada over the past decade (AASHE, 2010; Wright, 2011). Sustainability offices have focused primarily on the "greening" of operations (e.g., engaging in lighting retrofits, developing environmentally friendly procurement policies, and developing sustainable transportation and food plans), but many have also engaged in informal educational initiatives on campus (e.g., anti-idling campaigns, campus "green" days) (AASHE, 2010; Wright, 2011).

Sustainability-specific governing documents, such as campus-wide sustainability policies, plans or mandates, (hereafter referred to as policies) are seen as potentially important drivers of sustainability practices on campus (Nomura \& Abe, 2010; Sammalisto \& Arvidsson, 2005). In the past 10 years, there have also been significant efforts to benchmark Canadian universities in terms of their commitment to and performance on sustainability, including the Campus Sustainability Assessment Framework (CSAF), and the Association for the Advancement of Sustainability in Higher Education's (AASHE's) Sustainability Tracking Assessment and Rating System (STARS). In the early part of this century, more than 30 universities in Canada used CSAF, but its use has declined in the past few years with the emergence of STARS, which has become the dominant system in North America. Currently, 261 universities and colleges take part in STARS, including 28 Canadian postsecondary institutions. While STARS and CSAF are predominant on North American campuses, many other assessment tools are used around the world, including the Assessment Instrument for Sustainability in Higher Education (AISHE), used widely in Europe (Roorda \& Martens, 2008), and the Alternative University Appraisal (AUA), used widely in the Asia-Pacific region (Fadeeva \& Mochizuki, 2010).

In addition, we examine the relationship between the existence of an environment/ sustainability policy and the presence or absence of a sustainability office/officer, the production of a campus sustainability assessment, and the likelihood of being a signatory to an international sustainability in higher education (SHE) agreement. Further, we consider geographic location and community differences, political climate, the size of the university or its Maclean's magazine ranking, and whether any of these suggest a relationship with the presence of an environment/sustainability policy. Finally, we offer some insights with respect to environment/sustainability policies on university campuses, as well as some observations regarding their proliferation.

This census offers an overview of the aggregate of high-level sustainability-specific documents on Canadian campuses as a step toward a more detailed analysis. Note that the paper does not look at the content or quality of the sustainability policy documents, nor does it investigate the extent to which the policies are practiced within the institution. The census is part of a larger six-year study from the Sustainability and Educational Policy Network (SEPN), which will use the census data as a baseline for undertaking an examination of the content in these policies, as well as examining the relationship between sustainability policy and practice in Canadian formal education.

\section{Methods}

This study focused on all PSE institutions $(n=220)$ affiliated with the Association of Universities and Colleges of Canada (AUCC) or with the Association of Canadian Community Colleges (ACCC). The census included both English and French PSE institutions. 
A database was created in which institutions were categorized as being a college or university, private or public, English or French-speaking, or an Aboriginal institution ${ }^{2}$. Data were also collected on the institution's geography (i.e., province or territory; community population; rural, urban, or suburban campus location), the size of its student population, and whether the institution had multiple campuses. An extensive web search was also completed to determine whether each institution had completed a sustainability assessment process (e.g., STARS or CSAF), signed the Talloires Declaration or the Halifax Declaration, put in place an environmental sustainability office or officer, or instituted an environmental or sustainability policy.

Data on campus locations, student population, and number of campuses were collected from annual reports (academic year 2011-2012), accessed via institution websites. Using the institution's website search engine, information was collected on the sustainability features of an institution, such as the presence or absence of a sustainability policy or plan, whether or not an institution had conducted a sustainability assessment, whether the institution was a signatory of a declaration on sustainability, and the presence or absence of a sustainability office or officer. A Boolean search was conducted with the institution's website search engine using the terms "sustain" or "environment" or "ecological" or "green" or "Aboriginal." Equivalent French terms were used on Francophone institution websites. The term "Aboriginal" was included within the search parameters, recognizing that sustainability or environmental priorities may be taken up using another language, depending on the cultural context.

Where the first round of basic term-search results did not include term variations, the following variations were entered into the website's search engine in Boolean fashion: "sustainable development" or "sustainability" or "sustainable" or "environmental" or "environmental sustainability" or "Indigenous" or "First Nations" or "Métis" or "Inuit." Any information gleaned regarding an institution's sustainability features (declarations, assessments, office or officer, and policies or plans) was added to the database. Because the policy sections of institutional websites frequently include scanned documents, each policy section was reviewed in its entirety for any relevance to environmental, sustainability, or green issues, or Aboriginal affairs, in order to ensure the inclusion of any document that may have been ignored by the text-based search. In addition, the search terms and the term variations were all entered into the Google engine in a Boolean fashion along with the institution's name (e.g., McGill University and sustainability) to ensure webbased searches were rigorous.

If the information sought was not available on the institution's website, researchers contacted the office of the Vice President Administration by phone. In addition, SEPN partners from AASHE and from the Sierra Youth Coalitions were consulted in order to confirm which Canadian institutions had participated in the STARS rating system and CSAF.

Once these data were collected, a stacked histogram was constructed to display the total number of PSE institutions per province/territory in relation to the total number of PSE institutions with a sustainability policy per province/territory. Using a subset of the previous data, another series of stacked histograms were constructed. These display the total number of PSE institutions with sustainability policies per province/territory in relation to the total number of PSE institutions within this subset that possessed a given sustainability feature, such as a completed sustainability assessment, or the presence of a designated sustainability office or officer. 
Measures of association between the variables were conducted using an $R$ statistical software package. First, the data were transformed toward normality using various power transformations. Then, conditional density plots were constructed in order to explore the relationship between the presence or absence of an environmental/sustainability policy on one hand, and the institution's latitude, student population, and size of its host city's population on the other. In order to identify any relationships, pairwise comparisons between dichotomous variables were conducted using a $2 \mathrm{X} 2$ contingency table to calculate $\Phi$, the degree of association between the two binary variables. For contingency tables larger than 2X2 (such as contingency tables looking at presence or absence of policy at an institution $(n=2)$ against the province/territory in which the institution was located $(n=$ 13)), Cramer's V was used to calculate the degree of association between the two nominal variables. For both $\Phi$ and V, a measure of o indicates no relationship, while a measure of 1 indicates a perfect relationship.

A best-fit linear regression was calculated for a scatter plot of data examining provincial sustainability rankings from the Corporate Knights sustainability report cards and the percentage of PSE institutions in a given province that posses an environment/sustainability policy. Finally, we investigated the presence of local or provincial legislation relating to sustainability and whether or not these policies could be related to sustainability policy uptake in provincial PSE institutions.

\section{Results}

\section{Examining Regional Trends in the Presence of Sustainability Policies}

As Figures 1 and 2 illustrate, some geographical differences are apparent, whether latitude, or political (provincial or territorial) boundaries. The data shows that PSE institutions maintain such policies at a decreasing rate as you move north (Figure 1). It should be noted that conditional density becomes less reliable when there are fewer "x observations," that is, where fewer latitudes are represented. In other words, the smoothed line is less accurate in high latitudes, which are represented by relatively few institutions (only three above the 6oth parallel). However, the overall trend remains solid: a decreasing likelihood of having an environmental/sustainability policy the farther north the institution is located.

Quebec and British Columbia have the highest proportion of PSE institutions that have adopted environment/sustainability policies, with $85 \%$ and $67 \%$ respectively. They are also two of the three provinces with the highest number of institutions having policies, with 50 and 18 respectively (Figure 2). Ontario also has a high number of institutions with policies $(n=22)$, but these represent only 37\% of all PSE institutions in the province. On the other end of the spectrum, only one out of seven PSE institutions (14\%) in New Brunswick has an environment/sustainability policy, and in Saskatchewan, only 2 of 15 possible PSE institutions (13\%) have policies.

None of the three ACCC-accredited PSE institutions in the Northern Territories has an environment/sustainability policy. None of these have sustainability officers/officers; none have conducted an institution-wide sustainability assessment, nor any signed a national or international declaration on sustainability in higher education. For this reason, little analysis regarding PSE institutions in the territories has been included. 


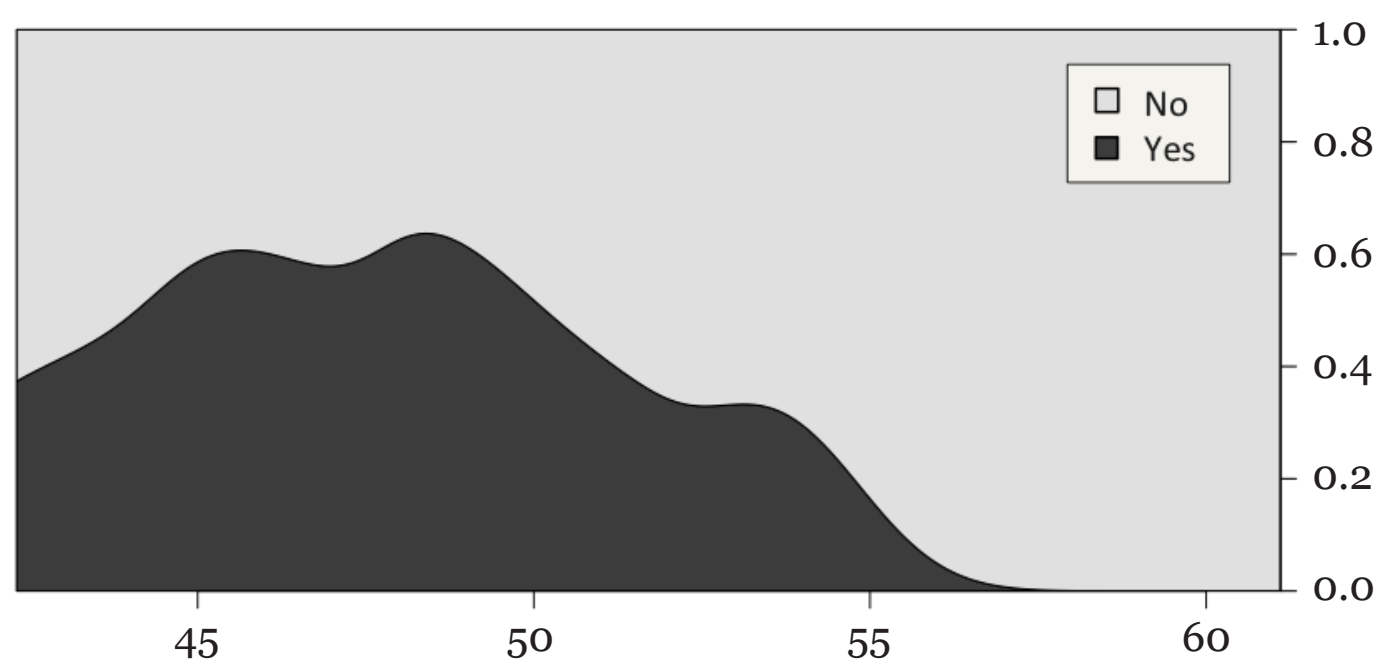

Figure 1. Conditional-density plot of policy and latitude. X-axis indicates latitude. Y-axis indicates percentage of PSE institutions that have a sustainability policy.

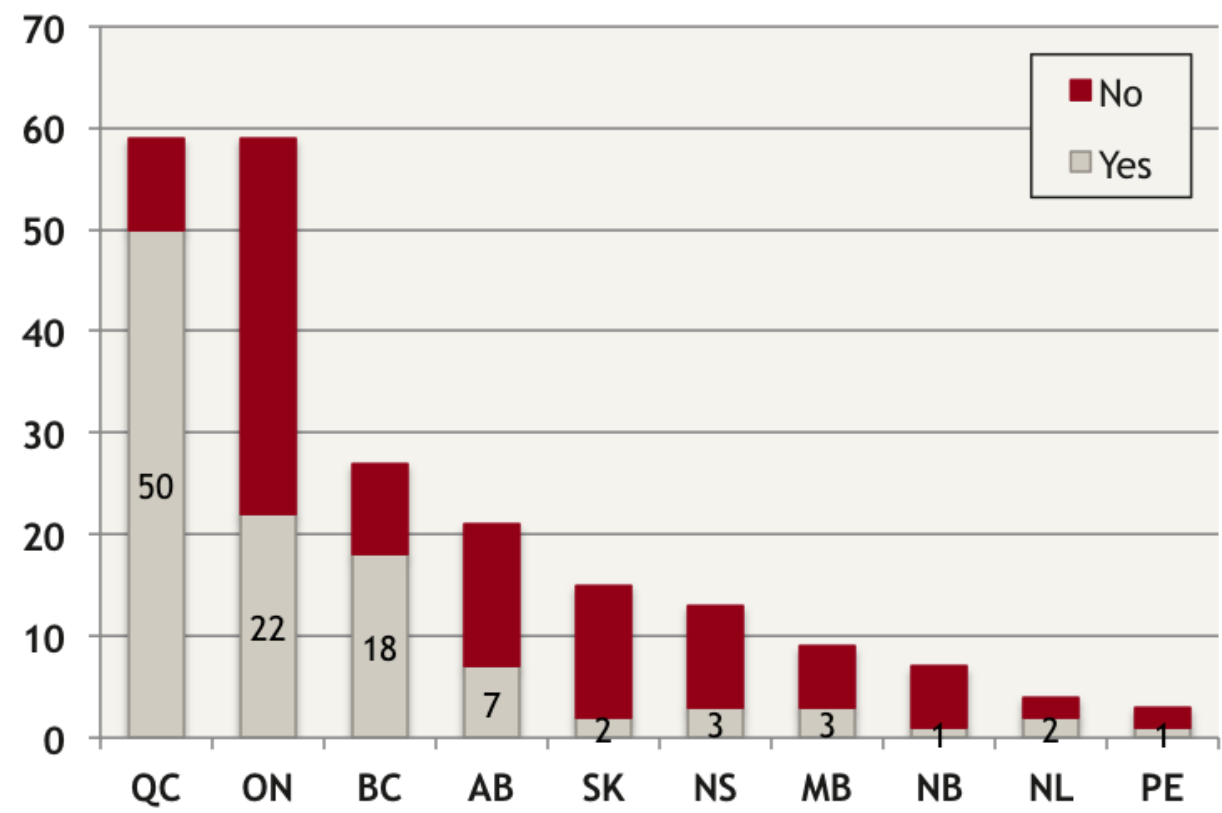

Figure 2. Histogram of the number of PSE institutions per province, with a subset of PSE institutions that have an environment/sustainability policy and/or plan. BC and QC schools are more likely to have policies.

\section{Does Having a Policy Correlate with Signing an International or National Sustainability Declaration?}

International declarations for sustainability in higher education are often seen as containing guiding principles and commitments that can help postsecondary institutions incorporate sustainability (Sylvestre, et al,, 2013). However, our data show that the rela- 
tionship between having an environmental/sustainability policy and being a signatory is not a strong one. It is interesting to note that only $14 \%(n=31)$ of the 220 Canadian PSE institutions we investigated for this study have actually signed any international declaration at all. (Figure 3)

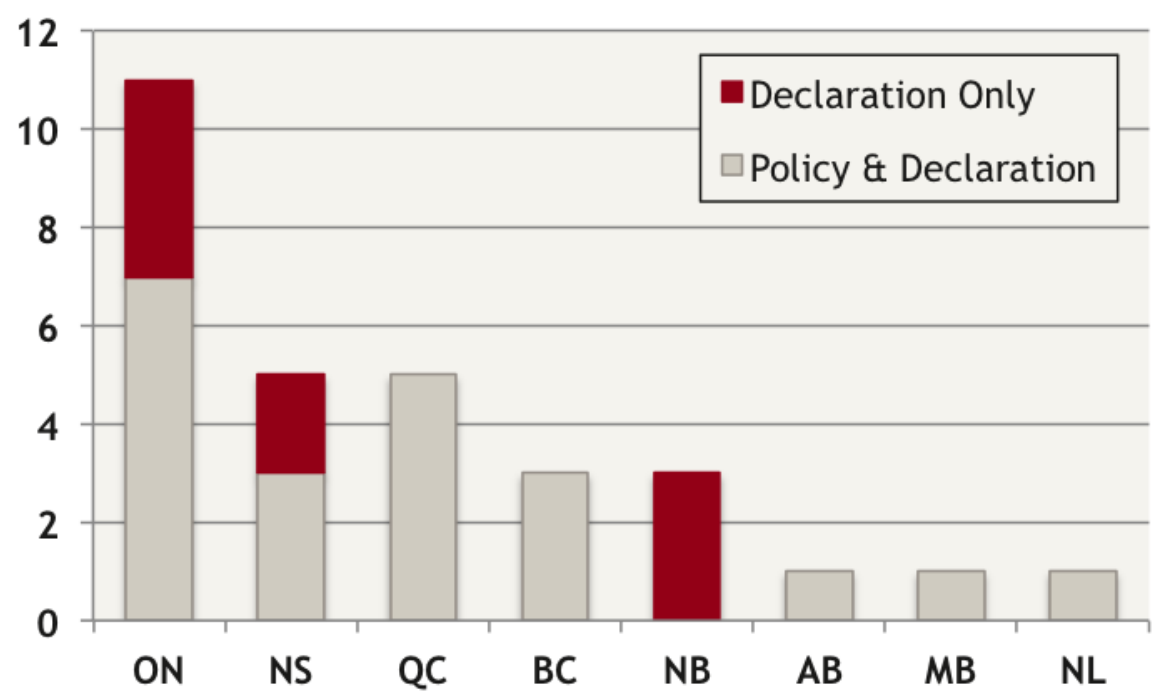

Figure 3. Histogram of the 31 PSE institutions that have signed international declarations (Talloires or Halifax) on sustainability in higher education, by province.

Of the 31 institutions that had signed either the Talloires Declaration or the Halifax Declaration (or both), only 21 had a high-level sustainability policy. All of the Québec institutions $(n=5)$ that signed a declaration had an environmental/sustainability policy, as did all of the institutions from British Columbia $(n=3)$, Alberta $(n=1)$, Manitoba $(n=1)$, and Newfoundland and Labrador $(n=1)$. Although three institutions from New Brunswick signed a declaration, none of these had institution-wide policies related to environment/sustainability. Examining international declarations pertaining to sustainability in higher education created after the Talloires and Halifax Declarations, even lower levels of participation from Canadian institutions can be observed. Of the 272 PSE institutions that signed the Commitment to Sustainable Practices of Higher Education Institutions on the Occasion of the United Nations Conference on Sustainable Development in 2012, only two were Canadian (Simon Fraser University and Université Laval). Only a single Canadian institution (the University of British Columbia) was signatory to the International Sustainable Campus Network Charter at the time of this writing.

Sustainability-in-higher-education declarations have been criticized in the past for being too general in their statements and for providing "no teeth" with which to implement them on campus (Walton, 2000; Wright, 2003). While it is beyond the scope of this paper to investigate, one could postulate that some Canadian PSE institutions investigated have been more interested in developing policies within their own institutions than adopting the more generic international statements of intention present in declarations. Alternatively, by avoiding signing, institutions are avoiding commitment to the terms of the declarations. In addition, our data show that the relationship between having an en- 
vironmental sustainability policy and being signatory to a national declaration is even weaker. Of the 59 PSE institutions that signed onto the Pan-Canadian Protocol on Sustainability, only 32 possessed an environmental/sustainability policy.

\section{Does Having a Policy Correlate with Having a Campus Sustainability As- sessment?}

In contrast to the much lower percentage that have signed international declarations, 93 of the 220 institutions (42\%) have completed at least one campus sustainability assessment (i.e., STARS, CSAF, CÉGEP Vert, etc.). Of all of the PSE institutions within Canada that have a policy $(n=110)$, approximately $74 \%(n=81)$ have completed at least one campus sustainability assessment (Figure 4 ).

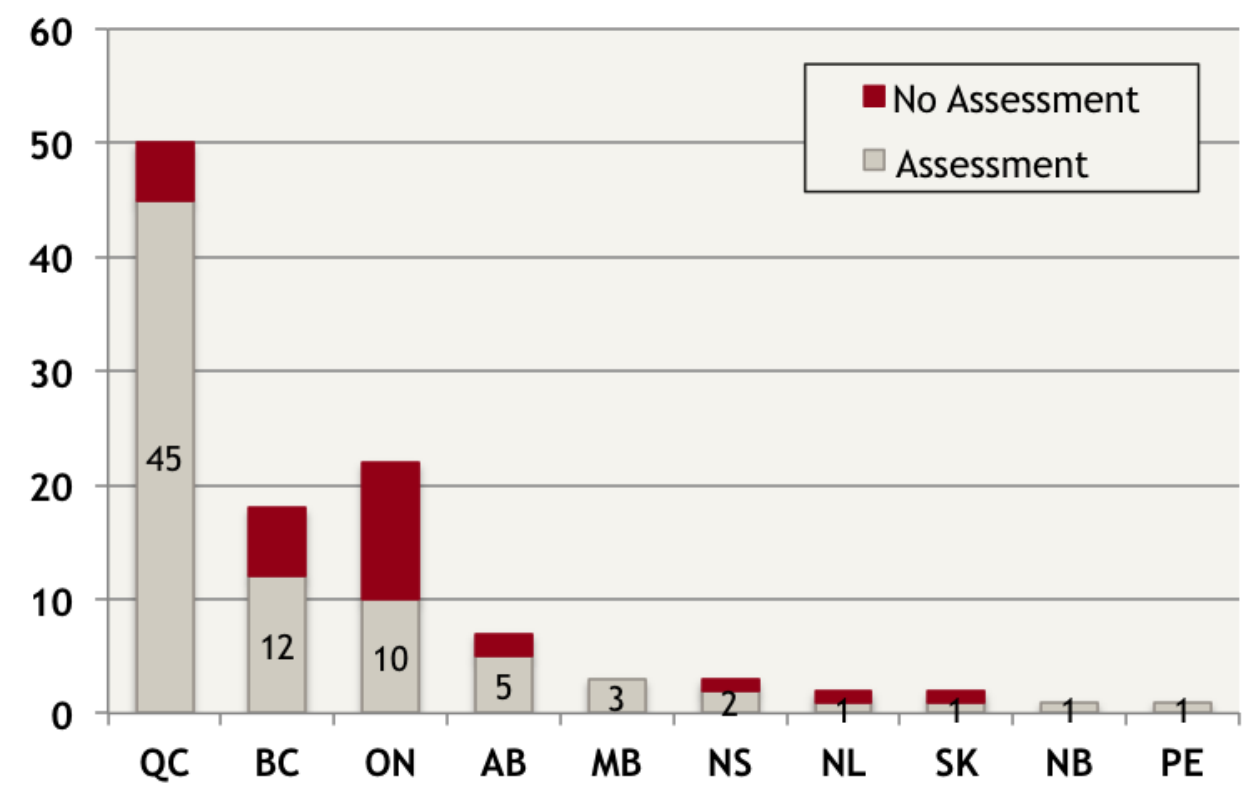

Figure 4. Histogram of the number of PSE institutions with an environment/sustainability policy and/or plan that have completed at least one campus sustainability assessment.

In contrast, of PSE institutions that do not have a policy ( $n=110)$, only $11 \%(n=12)$ have undertaken assessments. The data can be further delineated according to province. The provinces that have the strongest relationship between the existence of an environment/sustainability policy and having completed a campus sustainability assessment are Manitoba, New Brunswick, Prince Edward Island, and Québec. However, Québec is the only one of these provinces with a substantial number of PSE institutions.

\section{Does Having a Policy Correlate with the Presence of a Sustainability Office/ Officer?}

Our analyses revealed that only 77 (35\%) of all 220 PSE institutions had a sustainability office and/or officer (sometimes referred to as director) to oversee sustainability initiatives on campus. Of the 110 Canadian-accredited PSE institutions that have environment/sustainability policies, we found that $61 \%(n=67)$ also have sustainability offices or 
officers (Figure 5). In sharp contrast, only 9\% $(n=10)$ of those institutions that do not have an environment/sustainability policy have sustainability offices or officers.

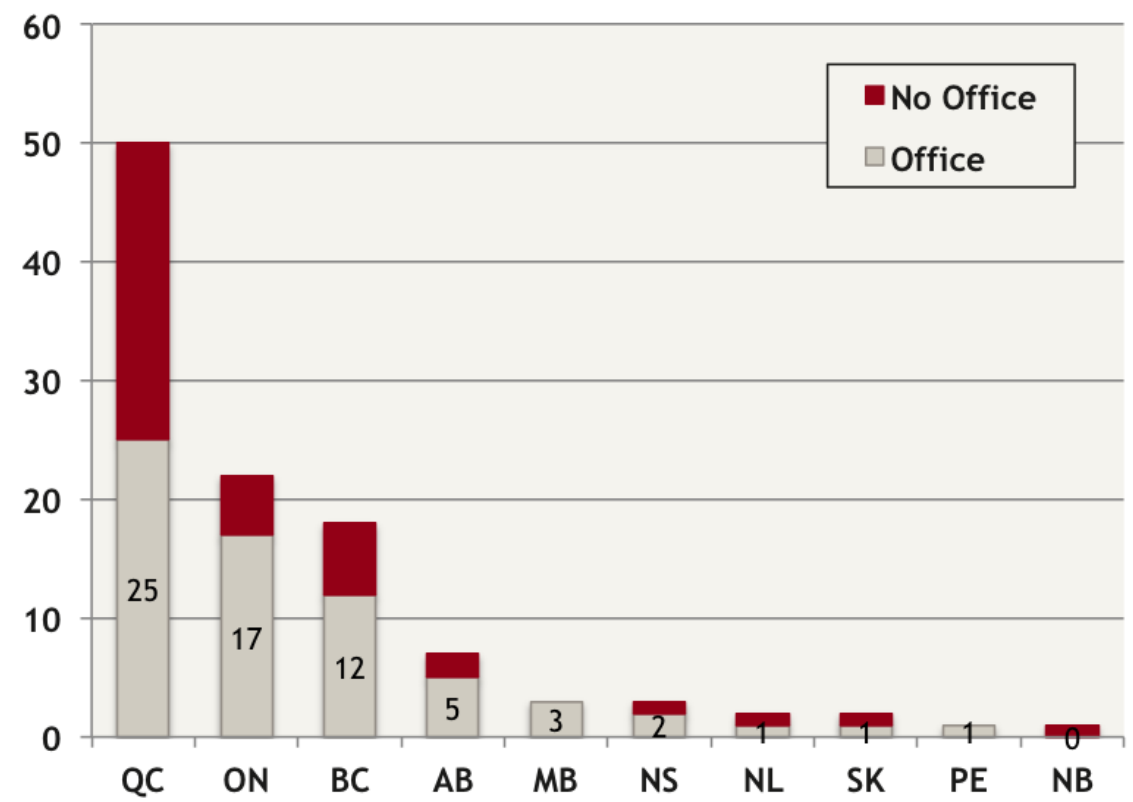

Figure 5. Histogram of the number of institutions with an environment/sustainability policy that also have a sustainability office or officer.

\section{Does Size Matter?}

Figure 6 shows that the likelihood of having an environmental/sustainability policy increases consistently with the size of the city in which the institution is located, with the majority of those PSE institutions that have a policy being located in an urban area with a population of over 500,000 (e.g., Montréal, Toronto, Vancouver).

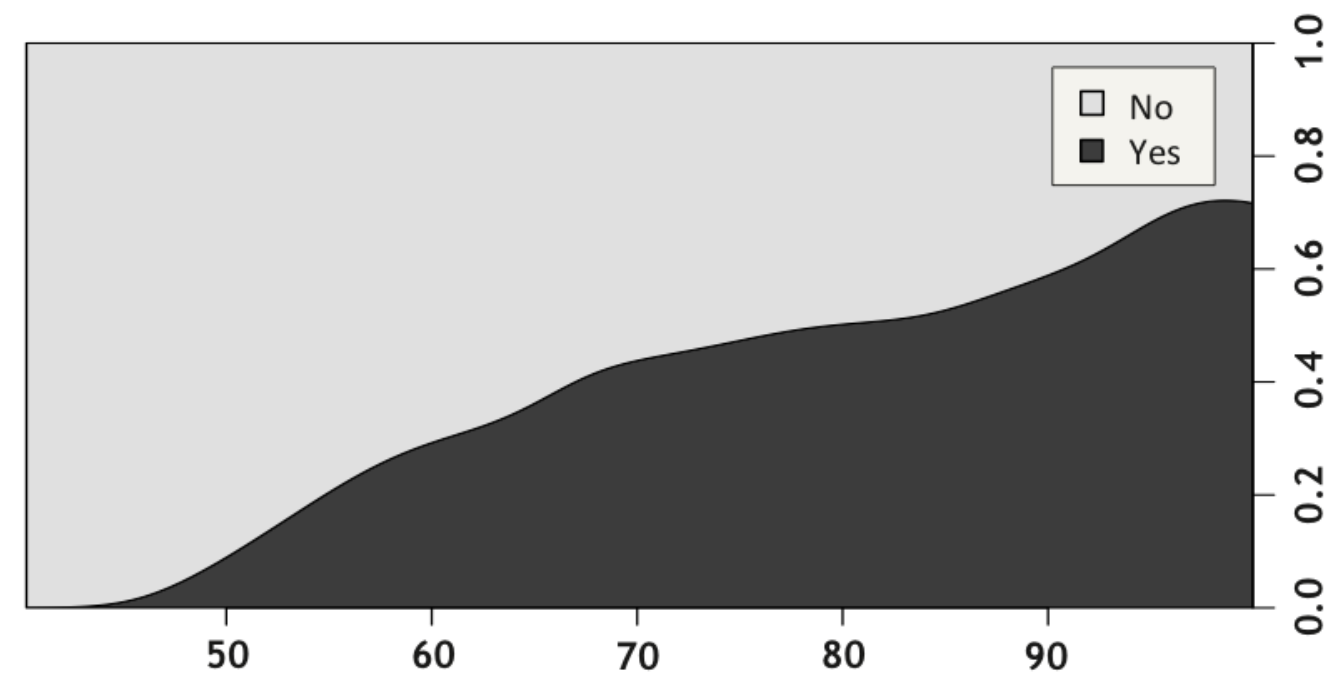

Figure 6. Conditional density plot of policy and city population. Large cities more frequently have policies. X-axis indicates city population (in thousands). Y-axis indicates percentage of PSE institutions in city with a sustainability policy. 
Regarding the size of the institution's student population in relation to environmental/sustainability policy uptake, the likelihood of having a policy would appear to increase with the size of the student population of the institution. However, the relationship is not as strong as the relationship between city population and presence of policy. PSE institutions with very large student bodies appear to have a large number of part-time students, which might complicate interpretation of the far-right side of the figure. In addition, a large proportion of the PSE institutions with an environmental/sustainability policy are Quebec's smaller (student populations < 5,000) CÉGEPs, which explains the large number of institutions seen at the other end of the spectrum. We suspect that the large number of CÉGEPs in Québec with environmental/sustainability policies obscures a clear, nation-wide trend of larger institutions being more likely to have policies.

\section{Is There a Relationship between Having a Policy and the Maclean's Maga- zine Rankings?}

For the past 22 years, Maclean's magazine in Canada has released annual rankings of Canadian universities. The primary aim of the rankings is to inform potential PSE applicants about Canadian universities based on a range of criteria that includes student body characteristics, classes, faculty, finances, library, and reputation. The rankings are split into three categories: schools that focus on undergraduate studies with few or no graduate programs (undergraduate), schools that have both extensive undergraduate studies and an extensive selection of graduate programs (comprehensive), and schools that have a professional medical program and a selection of graduate programs (medical-doctoral). In the last round of rankings, at the time of this writing, 19 institutions were ranked in the undergraduate category, 15 were ranked in the comprehensive category, and 15 were ranked in the medical-doctoral category. While the rankings have met with criticism (Schmidt, 2006; Samarasekaera, 2007), an abundance of evidence shows that universities are nevertheless preoccupied with attaining a high ranking for the sake of their public images.

Being a Maclean's-ranked school does not seem to be a strong predictor of the existence a policy or plan, but an interesting picture emerges when the Maclean's ranked institutions are examined within the confines of their three respective categories. Our analyses reveal that $100 \%(n=15)$ of the medical-doctoral universities ranked by $M a-$ clean's possess a high-level environment/sustainability policy. However, only 60\% ( $n=$ 9) of comprehensive universities had a sustainability policy or plan, and less than half of undergraduate institutions $(47 \%, n=9)$ have this type of high-level document. These results seem to indicate that there is no strong relationship between being an undergraduate institution and the uptake of a sustainability policy. However, with respect to medicaldoctoral universities the relationship appears to be strong. 


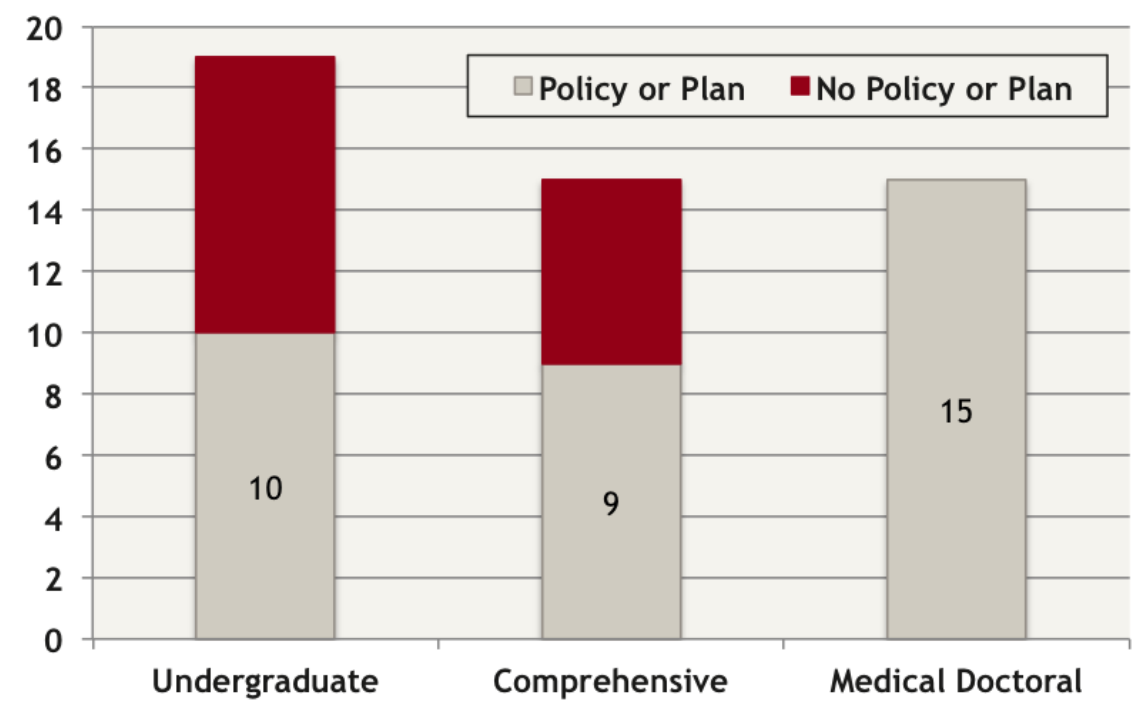

Figure 7. Maclean's-Magazine-ranked PSE institutions.

In addition, the Corporate Knights magazine's 2012 Green Provincial Report Card is used as an indicator of the "climate" of provincial policy related to sustainability in each province. This Green Provincial Report Card compares each province against 35 indicators addressing air and climate, water, nature, transportation, waste, energy and buildings, and innovation, using federally produced data to ensure consistency. While there is no perfect correlation between provinces with a higher rating on the Green Provincial Report Card, it is clear that the general outlook of provincial policy with respect to environment/sustainability is reflected in whether or not a high proportion of PSEs have environment/sustainability policies (Figure 8). The linear trend line inserted in the figure below suggests a small but positive relationship between the two variables.

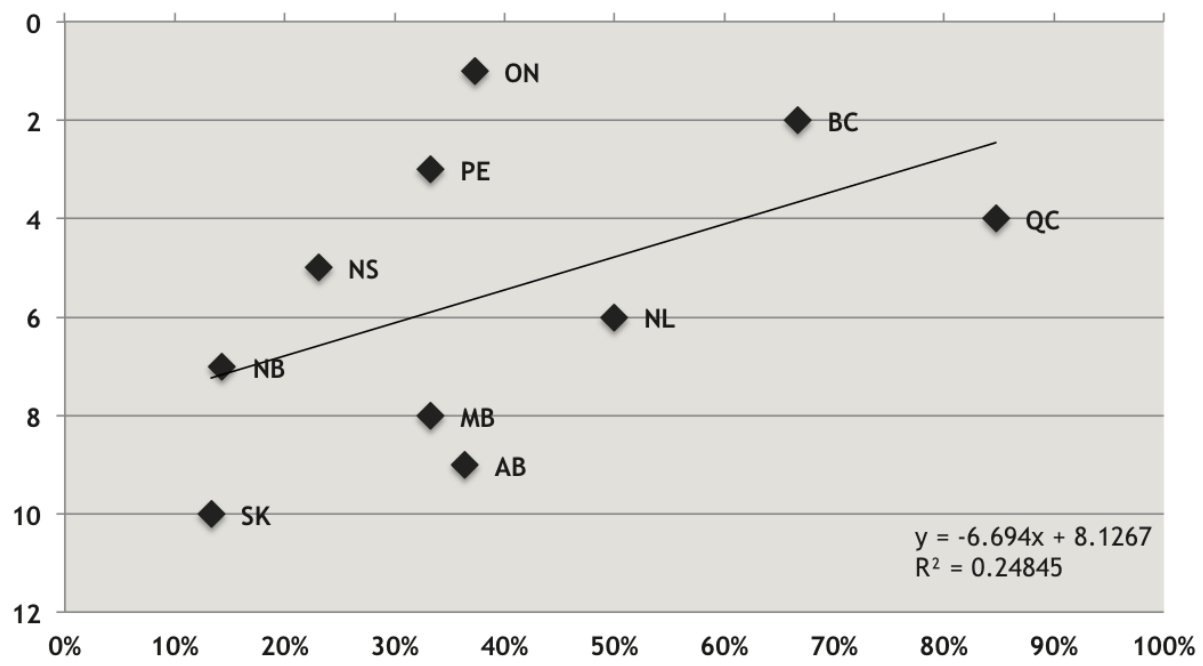

Figure 8: Relationship between Corporate Knights Green Report Card rankings and percentage of PSE institutions in a province that have an environment/sustainability policy 


\section{Discussion}

Our analysis shows that 110 of the 220 Canadian institutions investigated (50\%) have an environment/sustainability policy. While the term "environment" was a popular choice in the 1990s, our data show that the terms "sustainability" and "sustainable development" begin to emerge in environment/sustainability policies beginning in the early 2000 s and continuing to the present. This change from the predominant use of "environment" toward the use of "sustainability" is echoed in the international literature as well (i.e., IISD, 2009; United Nations DESA/UNDP, 2012). This change in terminology within PSE institutions may simply represent a change in the terminology used in higher education, or it could actually indicate a transformation in thinking about environmental work on campus that expands into the social and economic spheres. An answer is beyond the scope of this analysis to determine, but future research content analysis of these policies could determine how terms are used across policies, and the degree to which the understandings of environment and sustainability may have changed over the past decades.

While it is beyond the scope of this paper to investigate the actual causes of the many provincial differences that emerge from the data, some extraneous factors point to why certain provinces have more PSE institutions with environment/sustainability policies than others. To begin with, a large number of Québec's CÉGEPs maintain a provincewide CÉGEP Vert program (Environnement jeunesse, n.d.) that requires at minimum from participating schools a draft of an environment/sustainability policy for the campus. Forty-eight schools participate as of 2013, and most of these are ACCC accredited. This high participation rate of smaller schools in the CÉGEP Vert program is likely the reason for this divergence from the national trend.

Speculating on cause-and-effect with respect to PSEs and a province's performance with respect to the Green Provincial Report Card, a two-way flow of influence can be detected. If the presence of an environment/sustainability policy within a PSE institution is an indicator of the culture of the institution, and its graduates are influenced by this culture, these graduates might subsequently influence the direction of the policies of the provincial government. Alternatively, the general culture of a given provincial population may influence the political mandate there, which may in turn influence the direction of PSE institutional policies. A pairwise comparison between province and presence of an environmental/sustainability policy using Cramer's $\mathrm{V}$ as a measure of association between the two variables shows a value of $0.506 \mathrm{~V}$, a moderately positive relationship. Thus, while the province in which a PSE institution is situated may not be the determining factor as to whether an institution will have a policy, it does appear to be a contributing factor.

One specific example of a provincial policy impacting PSE institutional uptake of environment/sustainability policy is the influence of Quebec's Sustainable Development Act (2006), which requires that each public agency in the province outline how it will implement the Sustainable Development Act in a public document. While public colleges and universities are not classified as being public agencies under Québec's Auditor General Act (1985), the sheer number of government departments and other public agencies that are required to outline how they will implement the Sustainable Development Act may have encouraged PSE institutions to take the initiative and implement policies on their own. Under this scenario, PSE institutions may have seen an advantage in being early 
adopters of policy, and perhaps also a risk in being seen as laggards subject to eventual regulation under a new iteration of either the Sustainable Development Act or the Auditor General Act. While there are many factors that might influence the uptake of sustainability in PSEs, having a provincial government highlight and prioritize sustainability within its public agencies likely has an influence on the cultural awareness and acceptance of the concept. It is therefore not surprising to find in our data that Quebec has the highest percentage of PSE institutions that have an environment/sustainability policy.

Another example of potential provincial policy influencing whether a PSE institution will have environment/sustainability policies in place can be found in western Canada. British Columbia's Greenhouse Gas Emissions Target Act (2008) may have influenced an operational focus on energy and greenhouse gas emissions by all government organizations within the province. Under British Columbia's Budget Transparency and Accountability Act (2000), all public universities and colleges are defined as provincial government organizations and are therefore expected to comply with the Greenhouse Emissions Target Act. Indeed, all 25 public PSE institutions in British Columbia had a Climate Change Action Plan in which the institution outlined how it would lower greenhouse gas emissions on its campus(es) to below 2007 baseline levels by 2020 . In addition, 18 of these PSE institutions had broader sustainability policies that outlined institutional priorities around sustainability apart from and in addition to action on climate change. While no provincial act mandates the creation of sustainability policies beyond the scope of the institution's contribution to reducing greenhouse gases, it appears as though more broad ranging sustainability policies are implemented in tandem with or addition to PSE institutional climate action plans within British Columbia.

In contrast, while Ontario currently has a low percentage of PSE institutions that have an environment/sustainability policy, this may change in the near future. All public sector organizations in Ontario are required to report on their annual energy use and greenhouse gas emissions by July 1, 2013, and to develop five-year energy conservation and demandmanagement plans by 2014 (Green Energy Act, 2009). This broader provincial policy may have some influence on the development of environment/sustainability policies in Ontario PSE institutions in the near future and should be monitored. As with Québec, Ontario's public PSE institutions are not classified as public agencies; however, as with their neighbors to the east, Ontario PSE institutions may find it prudent to develop their own energy reduction policies to bring operations in line with other provincial agencies. Whether or not energy reduction initiatives will translate into the addition of broader sustainability policies, as is observed in British Columbia, only time will tell. Attention should also be brought to what role (if any) Manitoba's Sustainable Development Act (1998), Nova Scotia's Environmental Goals and Sustainable Prosperity Act (2007), and Newfoundland and Labrador's Sustainable Development Act (2007) have had on the uptake (or lack thereof) of environmental/sustainability policies in these respective provinces.

\section{Conclusions}

This analysis suggests a relatively strong relationship between having a sustainability policy and the presence of other sustainability initiatives, such as a sustainability assessment or a sustainability office/officer, on Canadian campuses. It also suggests a moderately positive relationship between the province in which a PSE institution is situated and 
the presence of an environment/sustainability policy, an indication that the provincial policy environment may influence the directions of higher education. However, it is important to note that this census has not established causation. The scholarly literature suggests that policy is often the driver of action in the case of environment/sustainability policies in Canadian PSE institutions. It may be however that in some cases, the creation of a policy was the result of hiring a sustainability officer, or becoming signatory to an international sustainability-in-higher-education declaration. Future research departing from this overview could include an investigation of any causal relationships between the existence of an environmental policy and other environment and sustainability initiatives on campus. For example, case studies that examine the historical context for sustainability initiatives at individual PSE institutions would be helpful in determining whether policies in PSE institutions really drive sustainability action and/or the extent to which initiatives/practice drive the development of policy documents. Further, investigations of the efficacy of environment/sustainability policies on campus (i.e. effectiveness of implementation) would be helpful to determine whether or how such policies could be created at individual PSE institutions. In addition, content analysis of the policies could provide insight into how sustainability is being understood, promoted, or acted upon, and how the various priorities of environment, social, and economic considerations are intended to be instituted through policies and associated practices.

A key finding of this analysis is that only 110 (50\%) of Canadian PSE institutions have an environment/sustainability policy. While this overview is merely a snapshot of current trends, it is a noteworthy fact that half of Canada's universities and colleges do not have an environment/sustainability policy at all. This is a surprising result, given the rate of uptake of sustainability policy in society, the potential role of PSE institutions as leaders in creating a sustainable future, and given that we are currently coming to the end of the United Nations Decade of Education for Sustainable Development (2005-2014), in which Canada participated. What does it say about Canadian postsecondary education's commitment to sustainability when half of our PSE institutions do not yet have a policy? If indeed education is the most powerful instrument society has to advance sustainable development, then these findings are an indication, albeit an inconclusive one, that society is not fully and effectively committed to advancing sustainable development. The finding is not conclusive because it is likely that many universities and colleges engage in prosustainability initiatives without a policy. It is also possible that some PSE institutions are still in the midst of developing their policies. Nevertheless, policies are important drivers of activity in public institutions and so the overall sentiment is that there is much work to be done, both by the governing bodies of individual institutions and the funding agencies. As such, this same study should be replicated at regular intervals to determine how the landscape of environmental/sustainability policy is changing.

Finally, there is a global movement and an emerging scholarly field in the area of sustainability in higher education. This study has provided a preliminary census of existing environment/sustainability policies in Canadian post-secondary institutions. We encourage the undertaking of similar studies in other countries and global regions to allow for both national and international comparisons, and ultimately, to inform the work of campus sustainability change-makers of the future. 


\section{Notes}

1. The Sustainability and Education Policy Network (SEPN) is a research-based partnership among academic research institutions and national and international organizations. The Network examines existing and new policies and innovations to determine which indicate the most promise for enabling educational change for a more sustainable future, including in relation to educational institutions' approaches to curriculum, research, facilities' operations, governance, and broader engagement with community and place.

2. A postsecondary education institution in Canada is classified as being Aboriginal if it meets the following criteria: 1) Board-directed- and controlled by Aboriginal communities; 2) Aboriginal faculty that ensure a holistic approach to education; 3) Infusion of First Nations culture, history, traditions, and values throughout the curriculum; 4) Methods of instruction that address Aboriginal learning styles; 5) Integration of community throughout the education process; 6) Aboriginal support staff that focus on creating student support networks; 7) Elder support and teachings; 8) Programs that ensure recognition and preservation of Aboriginal knowledge and history; and 9) Community-based program- and service delivery (Aboriginal Institutes' Consortium, 2005).

\section{Acknowledgements}

This paper draws on research supported by a Partnership Grant from the Social Sciences and Humanities Research Council of Canada (Grant No 895-2011-1025, Primary Investigator Dr. Marcia McKenzie). A list of team members and oganizational partners is included at www.sepn.ca.

A postsecondary education institution in Canada is classified as being Aboriginal if it meets the following criteria: 1) Board-directed- and controlled by Aboriginal communities; 2) Aboriginal faculty that ensure a holistic approach to education; 3) Infusion of First Nations culture, history, traditions, and values throughout the curriculum; 4) Methods of instruction that address Aboriginal learning styles; 5) Integration of community throughout the education process; 6) Aboriginal support staff that focus on creating student support networks; 7) Elder support and teachings; 8) Programs that ensure recognition and preservation of Aboriginal knowledge and history; and 9) Communitybased program- and service delivery (Aboriginal Institutes' Consortium, 2005).

\section{References}

AASHE (Association for the Advancement of Sustainability in Higher Education). (2010). Higher Education Sustainability Staffing Survey. Denver, CO: AASHE.

Aboriginal Institutes' Consortium (2005). Aboriginal institutions of higher education: A struggle for the education of Aboriginal students, control of Indigenous knowledge, and recognition of Aboriginal institutions. Toronto, ON: Canadian Race Relations Foundation.

Alshuwaikhat, H. M. \& Abubakar, I. (2008). An integrated approach to achieving campus sustainability: Assessment of the current campus environmental management practices. Journal of Cleaner Production, 16 (16), 1777-1785. 
Auditor General Act. (1985). Government of Quebec. Retrieved from https://www. canlii.org/en/qc/laws/stat/rsq-c-v-5.01/latest/rsq-c-v-5.01.html

Barlett, P. F. \& Chase, G. W. (2004). Sustainability on campus: Stories and strategies for change. Cambridge, MA: The MIT Press

Budget Transparency and Accountability Act. (2000). Government of British Columbia. Retrieved from http://www.bclaws.ca/civix/document/id/complete/statreg/o0023_01

Clugston, R. M., \& Calder, W. (1999). Critical dimensions of sustainability in higher education. In W. Leal Fihlo (Ed.), Sustainability and university life. (31-46). Frankfurt, Germany: Peter Lang.

Cortese, A. D. (2003). The critical role of higher education in creating a sustainable future. Planning for Higher Education, (31)3, 15-22.

Dryzek, J. S. (2005). The politics of the earth: Environmental discourses. New York, NY: Oxford University Press.

Ehrlich, P. R., \& Ehrlich, A. H., (2013). Can a collapse of global civilization be avoided ? Proceedings of the Royal Society Biological Sciences, 280, 1754-1763.

Environnement Jeunesse. (n.d.). CÉGEPs et Collèges Certifiés. In Cégep Vert du Québec. Retrieved from http:// http://enjeu.qc.ca/Certifications.html

Fadeeva, Z., \& Mochizuki, Y. (2010). Higher education for today and tomorrow: University appraisal for diversity, innovation and change towards sustainable development. Sustainability Science, 5 (2), 249-256.

GreenEnergy Act.(2009). Government of Ontario. Retrieved May 23, 2013, from http:// www.e-laws.gov.on.ca/html/source/regs/english/2011/elaws_src_regs_r11397_e.htm

Greenhouse Gas Reductions Target Act. (2008). Government of British Columbia. Retrieved from http://www2.gov.bc.ca/gov/topic.page?id=6oE1E7810BC145C6B6FCoo EE31F41EC5\&title=Climate\%20Action\%20Legislation\#GGRTA

Hopwood, B., Mellor, M., \& O’Brien, G. (2005). Sustainable development: mapping different approaches. Sustainable Development, 13(1), 38-52.

IISD (International Institute for Sustainable Development). (2009). Sustainable development timeline. Retrieved from https://www.iisd.org/pdf/2009/sd_timeline_2009. pdf

IPCC (Intergovernmental Panel on Climate Change). (2012). Managing the risks of extreme events and disasters to advance climate change adaptation. A special report of Working Groups I and II of the Intergovernmental Panel on Climate Change. Retrieved from http://www.ipcc-wg2.gov/SREX/images/uploads/SREX-All_FINAL.pdf

Leduc, T. (2010). The fallacy of environmental studies? Critiques of Canadian interdisciplinary programs. Environments: A Journal of Interdisciplinary Studies, 37(2), $1-23$.

Lozano, R., Lukman, R., Lozano, F. J., Huisingh, D., \& Lambrechts, W. (2013). Declarations for sustainability in higher education: Becoming better leaders, through addressing the university system. Journal of Cleaner Production, 48, 10-19. 
M'Gonigle, M., \& Starke, J. (2006). Planet U. Gabriola Island, BC : New Society Publishers.

Moore, J. (2005). Policy, priorities and action: A case study of the University of British Columbia's engagement with sustainability. Higher Education Policy. 18: 179-197.

Nomura, K., \& Abe, O. (2010). Higher education for sustainable development in Japan: Policy and progress. International Journal of Sustainability in Higher Education, 11, 120-129.

Orr, D. W. (1992). Ecological literacy: Education and the transition to a postmodern world. Albany, NY: SUNY Press.

Rees W. (2010). What's blocking sustainability? Human nature, cognition, and denial. Sustainability: Science, Practice, and Policy, 6(2), 13-25.

Robinson, J. (2004). Squaring the circle. Ecological Economics, 48, 369-384.

Rockstrom, J., Steffen, W., Noone, K., Lambin, E., Lenton, T. M., Scheffer, M., Folke, C., et al. (2009). Planetary boundaries: Exploring the safe operating space for humanity. Ecology and Society, 14(2), 32-65.

Roorda, N., \& Martens, P. (2008). Assessment and certification of higher education for sustainable development. Sustainability, 1, 41-56.

Samarasekera, I. (2007). Rising up against rankings. Inside Higher Education. Retrieved from http://www.insidehighered.com/views/2007/04/02/samarasekera

Sammalisto, K., \& Arvidsson, K. (2005). Environmental management in Swedish higher education: Directives, driving forces, hindrances, environmental aspects and environmental coordinators in Swedish universities. International Journal of Sustainability in Higher Education, 6, 18-35.

Schmidt, S. (2 September 2006). Universities continue to shun Maclean's ranks. National Post. Retrieved from www.canada.com/nationalpost/news/story. html?id=876f5f10-322a-4e74-b768-0018ee6ecd 55\&k=11624

Sharp, L. (2002). Green campuses: The road from little victories to systematic transformation. International Journal of Sustainability in Higher Education 3(2), 128-145.

Sustainable Development Act. (2006). Quebec Ministry of Sustainable Development, Environment, and the Fight Against Climate Change Retrieved from http://www.mddelcc. gouv.qc.ca/developpement/loi_en.htm

Sylvestre, P., McNeil, R., \& Wright, T. (2013). From Talloires to Turin: A critical discourse analysis of declarations for sustainability in higher education. Sustainability, 5(4), 1356-1371.

UNESCO/Government of Greece. (1997). Thessaloniki Declaration. UNESCOEDP-97/CONF.401/CLD.2: Retrieved from http://unesdoc.unesco.org/ images/o011/o01177/117772eo.pdf

United Nations Department of Economic and Social Affairs (DESA) and United Nations Development Programme (UNDP). (2012). Synthesis of national reports for Rio +20. Retrieved from https://sustainabledevelopment.un.org/content/ documents/742RIO+20_Synthesis_Report_Final.pdf 
Vaughter, P., Wright, T., McKenzie, M., \& Lidstone, L. (2013). Greening the ivory tower: A review of education literature on research on sustainability in post-secondary education. Sustainability 5(5), 2252-2271;

Waas, T., Hugé, J., Verbruggen, A., \& Wright, T. (2011) Sustainable development: A bird's-eye view, Sustainability, 3, 1637-1661.

WCED (World Commission on Environment and Development). (1987). Our common future. Oxford, UK: Oxford University Press.

World Wildlife Fund. (2012). 2012 Living planet report: Summary. Gland, Switzerland: WWF. Retrieved from http://d2ouvy59podg6k.cloudfront.net/downloads/ lpr_2012_summary_booklet_final.pdf

Walton J. (2000). Should monitoring be compulsory within voluntary environmental agreements? Sustainable Development, 8(3),146-154.

Wright, T. (2003). A tenth year anniversary retrospect: The effect of the Halifax Declaration on signatory universities. Canadian Journal of Environmental Education 8 (1),_233-248.

Wright, T. (2004). The evolution of environmental sustainability declarations in higher education. In Wals, A., \& Corcoran, P. B. (Eds.). Higher education and the challenge of sustainability: Promise, practice, contestation, and critique (7-20). Dordrecht, Netherlands: Kluwer Academic Press.

Wright, T. (2006). Giving "teeth" to environmental policy. Journal of Cleaner Production, 12 (9-11), 761-168.

Wright, T. (2011). Sustainability in higher education - Perspectives from Canada and the United States. Barcelona, Spain: Global University Network for Innovation.

\section{Contact Information}

Philip Vaughter

College of Education

University of Saskatchewan

pcvaughter@gmail.com

Philip Vaughter is a postdoctoral fellow of the Sustainability Education Research Institute at the University of Saskatchewan. Philip's research focus is on understanding the roles of social systems in policy innovation and implementation in relation to environmental sustainability. Philip comes to the open prairies of Treaty 6 land from previous projects based out of the United States, Aotearoa/New Zealand, and Australia.

Tarah Wright is director of the Education for Sustainability Research Group and professor in the College of Sustainability and the Faculty of Science at Dalhousie University. Tarah conducts research within the field of education for sustainable development and she has published numerous papers covering a wide range of issues on sustainability in higher education. Tarah and her family make their home in the city of Halifax, on the traditional lands of the MicMac people, in the Acadian Forest Bioregion, at the edge of the Atlantic Ocean. 
Yuill Herbert is a director with Sustainability Solutions Group, a Canadian national workers' cooperative. Yuill has worked as a consultant on sustainability projects in the spheres of community planning, sustainability assessment, and on green buildings, including work with a number of universities and colleges. Yuill serves as a director on the boards of the Canada Research Chair on Sustainable Community Development, the Tatamagouche Community Land Trust and the Canadian Worker Co-operative Federation. 